RASĀYAN J. Chem.

Vol. 13 | No. 4 |2332-2339| October - December | 2020 ISSN: 0974-1496 | e-ISSN: 0976-0083 | CODEN: RJCABP

\title{
KINETICS OF SULFUR DIOXIDE ADSORPTION ON MODIFIED ACTIVATED COAL PRODUCED FROM PEACH SHELLS
}

\author{
Aizhan Mamyrbekova ${ }^{1}$, A.D. Mamitova ${ }^{2}$, M.K. Kassymova ${ }^{3}$, Aigul \\ Mamyrbekova $^{1, *}$, Zh.E. Daribayev ${ }^{4}$, R.E. Pralieva ${ }^{5}$, M.N. Yermakhanov ${ }^{3}$ \\ and G.S. Mutasheva ${ }^{6}$ \\ ${ }^{1}$ Department of Laboratory Disciplines, Dental Faculty/Khoja Akhmet Yassawi International \\ Kazakh-Turkish University, 29, B. Sattarkhanov Ave., Turkestan-161200, Kazakhstan \\ ${ }^{2}$ Department of Life Safety and Environmental Protection, Faculty of Construction and \\ Transport/Auezov South-Kazakhstan State University, 5, Tauke khan Ave., \\ Shymkent-160012, Kazakhstan \\ ${ }^{3}$ Department of Chemistry, Natural Scientific and Pedagogical Higher School/Auezov South- \\ Kazakhstan State University, 5, Tauke khan Ave., Shymkent-160012, Kazakhstan \\ ${ }^{4}$ Department of Ecology and Chemistry, Faculty of Natural Science/Khoja Akhmet Yassawi \\ International Kazakh-Turkish University, 29, B. Sattarkhanov Ave., \\ Turkestan-161200, Kazakhstan \\ ${ }^{5}$ Department of General Disciplines, Prefaculty/Khoja Akhmet Yassawi International Kazakh- \\ Turkish University, 29, B. Sattarkhanov Ave., Turkestan-161200, Kazakhstan \\ ${ }^{6}$ Department of Ecology and Life Safety, Faculty of Transport Engineering and Construction/ \\ Kazakh Transport and Communications Academy, 97, Shevchenko Street, \\ Almaty-050000, Kazakhstan \\ *E-mail: aigul.mamyrbekova@ayu.edu.kz
}

\begin{abstract}
The kinetics of sulfur dioxide adsorption on modified coal produced from the peach shell was investigated. It was determined the optimal conditions to produce modified activated coals for the processes of effective purification of gases from sulfur dioxide, confirmed by industrial tests. The most rapid adsorption of sulfur dioxide occurs on the shell treated by $\mathrm{ZnCl}_{2}$ (impregnation coefficient 0.4 ), followed by activation in the $\mathrm{CO}_{2}$ stream at a temperature of $773 \mathrm{~K}$, the pore size of which is easily accessible to sulfur dioxide molecules regardless of their molecular weight and structure. The values of the dynamic characteristics show that with the increase of particle size, the «value of the dead layer» - disabled - increases, therefore, with the increase of particle size, the dynamic activity of the adsorbent decreases. With the increase of the gas flow speed, the time of the protective action is significantly reduced, the process proceeds intensively.
\end{abstract}

Keywords: Adsorption, Sulfur Dioxide, Adsorbent, Gas Purification, Modified Activated Coal, Peach Shell.

(C) RASĀYAN. All rights reserved

\section{INTRODUCTION}

One of the toxic components released in huge quantities by industrial enterprises into the atmosphere as sulfur dioxide. The main sources of sulfur dioxide pollution are thermal power plants, ferrous and nonferrous metallurgy, chemical and oil refining industries. ${ }^{1-3}$ Sulfur-containing in fuels and ores turns into the aggressive gas during their combustion or processing. Preliminary desulfurization of fuel and ores cannot fully solve the problem of decreasing sulfur dioxide emissions into the atmosphere. In the chemical industry, the main source of atmospheric sulfur dioxide pollution is sulfuric acid production. ${ }^{4-6}$ The issue of sulfurous anhydride utilization from technological gases and its use for the production of

Rasayan J. Chem., 13(4), 2332-2339(2020)

http://dx.doi.org/10.31788/ RJC.2020.1345761

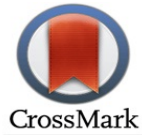


valuable products (sulfuric acid, elemental sulfur, liquid sulfurous anhydride), as well as the issue of reduction of the air basin pollution, should be given the great attention. ${ }^{7,8}$

Adsorbents are an effective tool for recuperation and neutralization of sulfur dioxide, and their capabilities in this direction have not been determined yet. Carbon porous materials are mainly used for recuperation of sulfur dioxide. ${ }^{9,10}$

Adsorption methods for separation and purification of substances in the liquid and gas phases require the selection of effective and cost-effective adsorbents. ${ }^{11-15}$

In recent years, numerous studies have focused on the use of carbon materials produced from fruit shells and rice husk. ${ }^{16,17}$ Often the used carbon materials do not correspond to the requirements of the technological process, in some cases, their use is economically unjustified, because of the high cost and insignificant raw material base. Therefore, the production of new efficient and cheap natural carbon materials from available industrial raw materials is one of the urgent tasks for scientists and technologists. A new promising raw material for the production of carbon-containing materials is vegetable raw materials, in particular the shells of fruit trees. ${ }^{18,19}$ Vegetable cellulose of the peach shell is low-carbon, and its high density determines the possibility of obtaining on its basis of firm adsorbents with a high specific surface area.

The production of cheap sorbents from food wastes can create the conditions for the introduction of new technologies and the decrease of harmful emissions into the environment. ${ }^{20-22}$ Also, the production of a wide range of powdered and granular sorbents from industrial wastes will allow us to obtain additional profits, as the necessity for such products at various enterprises is great.

\section{EXPERIMENTAL}

\section{Tribochemical Activation of Peach Shell in the Presence of Surfactant}

Production of activated coal was carried out by tribochemical activation of peach shell in a two-chamber shock-motion grinding mill in the presence of surfactant-alkylaryl sulfonate $\mathrm{RArSO}_{2} \mathrm{OM}$. Tribochemical activation results in multiple expansion of porosity and the formation of a fresh surface. ${ }^{23}$ After activation in the first chamber of the mill in the air the pore volume of the shells reaches $0.5 \cdot 10^{-4} \mathrm{~m}^{3} / \mathrm{kg}$ and in the second chamber of the mill in alkylaryl sulfonate the pores, volume reaches $1.8 \cdot 10^{-4} \mathrm{~m}^{3} / \mathrm{kg}$.

For the determination of the separate elements of peach shells, the elemental analysis was carried out, which showed that the shell consists of carbon $(76 \%)$, hydrogen $(23.586 \%)$, and nitrogen $(0.372 \%) .^{24,25}$

\section{Thermal Activation of Peach Shells}

Thermal activation of peach shells was carried out in a furnace for activation in the atmosphere of carbon dioxide $^{26}$. The temperature of the furnace was measured by a platinum-rhodium-platinum thermocouple, regulated by a thermoregulator. Activation was conducted at temperatures $573-1273 \mathrm{~K}$ with heating during 1-4 hours. Heat-treated samples of peach shells before measuring their adsorption properties were preserved in hermetic conditions.

\section{Chemical Activation of Peach Shells}

For the chemical activation of peach shells, equipment consisting of flask, electric heater, reverse refrigerator and thermometer was used ${ }^{27,28}$. Before chemical treatment, the mechanoactivated shell was sifted through a sieve of $0.1 \mathrm{~mm}$. Further, the chemical activation of the shell was carried out by sulfuric, hydrochloric, phosphoric acids and zinc chloride. After the samples were washed with hot distilled water, then dried at $378 \mathrm{~K}$ for 2 hours, then the shell was cooled in a desiccator.

\section{Studies of Sulfur Dioxide Adsorption}

For research of the adsorption extraction of sulfurous anhydride as the adsorbent, we used the peach shells activated by zinc chloride with the impregnation coefficient from 0.2 to 0.6 , followed by heat treatment at temperatures from $573 \mathrm{~K}$ to $873 \mathrm{~K}$ in the $\mathrm{CO}_{2}$ stream. To study the mass transfer issues during the adsorption of sulfurous anhydride, we used the experimental device, the main part of which is a glass tube with an internal diameter of $25 \mathrm{~mm}$ and a total height of $200 \mathrm{~mm}$. The chosen diameter of the 
RASĀYAN J. Chem.

Vol. 13 | No. 4 |2332-2339| October - December | 2020

dynamic tube was dictated by the necessity to achieve the uniformity of the flow distribution over the tube cross-section and to ensure the thermostat of the layer during the experiment.

\section{RESULTS AND DISCUSSION}

The results of studies of sulfur dioxide adsorption are shown in Table-1 and Fig.-1, at the initial mass concentration equal to $12 \%$ (vol). The best adsorption capacity on sulfur dioxide has the shells activated at a temperature of $\mathrm{CO}_{2}-773 \mathrm{~K}$ and subsequently activated by $\mathrm{ZnCl}_{2}$ with the impregnation coefficient $(0.4 ; 0.5 ; 0.3)$ and, as well as the shells activated at a temperature of $\mathrm{CO}_{2}-873 \mathrm{~K}$ and subsequently activated by $\mathrm{ZnCl}_{2}$ with the impregnation coefficient -0.4 . These adsorbents almost completely remove sulfur dioxide from the initial gas stream.

Table-1: Characteristics of the Adsorption Values of Sulfur dioxide From the Gas Medium by Activated Peach Shells

\begin{tabular}{|c|c|c|c|}
\hline $\begin{array}{c}\text { Impregnation Coefficient } \\
\text { of } \mathrm{ZnCl}_{2} \\
\end{array}$ & $\begin{array}{c}\text { Temperature of } \\
\text { Activation of } \mathrm{CO}_{2}, \mathrm{~K}\end{array}$ & $\begin{array}{c}\text { Pressure } \\
\text { (millimeter of mercury) }\end{array}$ & $\begin{array}{c}\text { Adsorption value } \\
\alpha, \% \text { (weight) }\end{array}$ \\
\hline \multirow[t]{4}{*}{ ( } & \multirow{4}{*}{773} & 4 & 4.2 \\
\hline & & 8 & 7.7 \\
\hline & & 12 & 9.6 \\
\hline & & 16 & 9.8 \\
\hline \multirow{4}{*}{0.3} & \multirow{4}{*}{773} & 4 & 5.1 \\
\hline & & 8 & 9.3 \\
\hline & & 12 & 11.8 \\
\hline & & 16 & 12.3 \\
\hline \multirow{4}{*}{0.4} & \multirow{4}{*}{573} & 4 & 3.6 \\
\hline & & 8 & 6.7 \\
\hline & & 12 & 8.0 \\
\hline & & 16 & 8.5 \\
\hline \multirow{4}{*}{0.4} & \multirow{4}{*}{673} & 4 & 2.5 \\
\hline & & 8 & 5.2 \\
\hline & & 12 & 7.2 \\
\hline & & 16 & 7.6 \\
\hline \multirow{4}{*}{0.4} & \multirow{4}{*}{773} & 4 & 8.5 \\
\hline & & 8 & 12.1 \\
\hline & & 12 & 13.9 \\
\hline & & 16 & 14.8 \\
\hline \multirow{4}{*}{0.4} & \multirow{4}{*}{873} & 4 & 7.0 \\
\hline & & 8 & 11.1 \\
\hline & & 12 & 13.2 \\
\hline & & 16 & 14.2 \\
\hline \multirow{4}{*}{0.5} & \multirow{4}{*}{773} & 4 & 6.2 \\
\hline & & 8 & 10.5 \\
\hline & & 12 & 13.0 \\
\hline & & 16 & 14.0 \\
\hline \multirow{4}{*}{0.6} & \multirow{4}{*}{773} & 4 & 3.1 \\
\hline & & 8 & 5.6 \\
\hline & & 12 & 7.4 \\
\hline & & 16 & 8.0 \\
\hline
\end{tabular}

As it is seen from the data of Fig.-2, the most rapid adsorption of sulfur dioxide occurs on the peach shell, activated by $\mathrm{ZnCl}_{2}$ with the impregnation coefficient of $\mathrm{ZnCl}_{2}$ equal to 0.4 and subsequently activated by heat at a temperature of carbon dioxide equal to $773 \mathrm{~K}$. The pore sizes, in this case, are easily accessible to sulfur dioxide molecules, regardless of their molecular weight and structure. This is also due to the previously identified features of the crystal-chemical structure of the adsorbent. Maximum adsorption of sulfurous anhydride on activated shells occurs in 1.5-2 hours, but already at one-hour gas-phase contact of the adsorbent with the gas mixture, we observe the sorption values $(85-90) \%$ from the maximum 
RASĀYAN J. Chem.

Vol. 13 | No. 4 |2332-2339| October - December | 2020

achievable, which is due to the structure of sulfurous anhydride and the presence of selectively adsorbed functional groups in it. Adsorption extraction of sulfurous anhydride under dynamic conditions was carried out at several heights of activated carbon layers: $0.01 \mathrm{~m} ; 0.03 \mathrm{~m} ; 0.06 \mathrm{~m} ; 0.09 \mathrm{~m} ; 0.12 \mathrm{~m}$. As the activated coal the fruit shell treated by zinc chloride with the impregnation coefficient equal to 0.4 and subsequently treated by heat with the temperature of $\mathrm{CO}_{2}$ equal to $773 \mathrm{~K}$ was used.

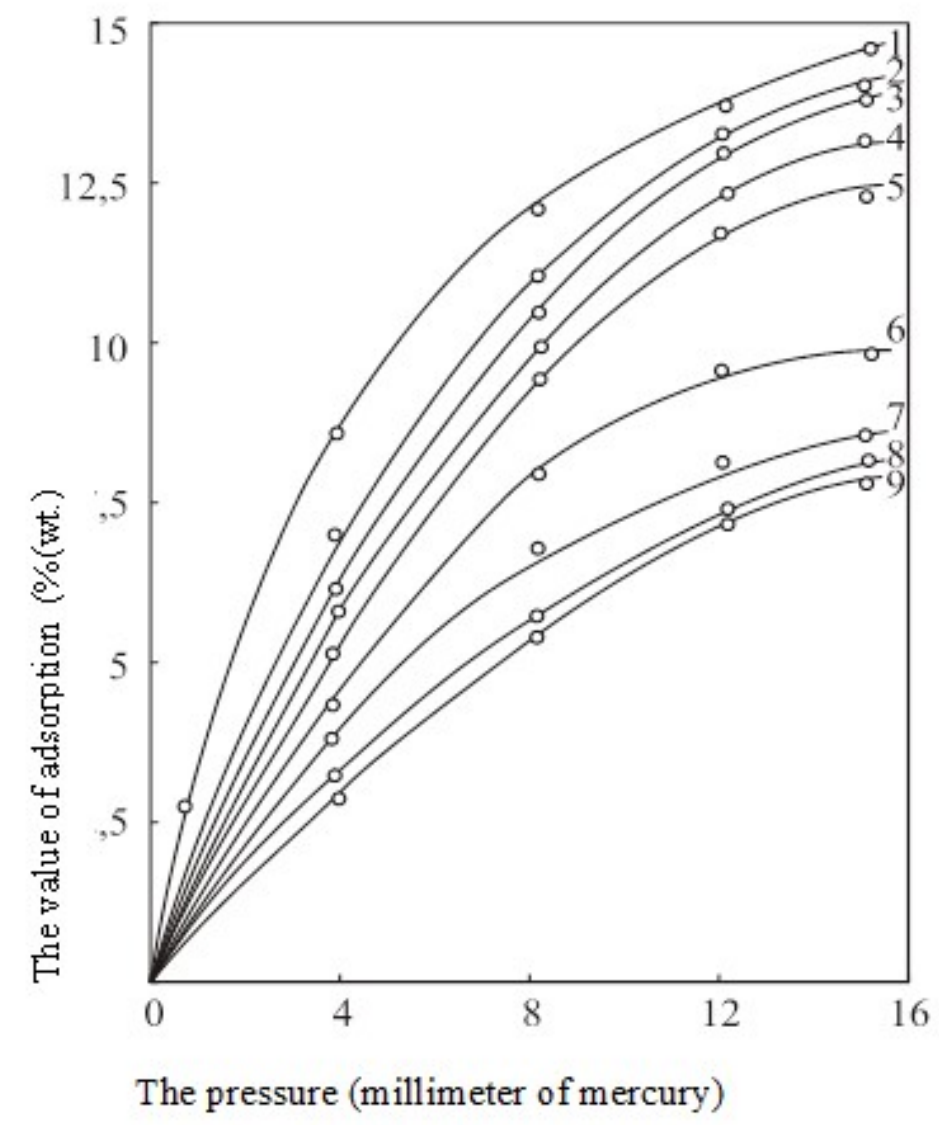

Fig.-1: Isotherms of Sulfur dioxide Adsorption on Activated Peach Shells: 1 - Impregnation Coefficient of $\mathrm{ZnCl}_{2}$ 0.4; $\mathrm{CO}_{2}$ Temperature -773 K; 2 - Impregnation Coefficient of $\mathrm{ZnCl}_{2}-0.4 ; \mathrm{CO}_{2}$ Temperature -873 K; 3 Impregnation Coefficient of $\mathrm{ZnCl}_{2}-0.5 ; \mathrm{CO}_{2}$ Temperature - $773 \mathrm{~K} ; 4$ - Industrial Adsorbent BAU; 5 Impregnation Coefficient of $\mathrm{ZnCl}_{2}-0.3 ; \mathrm{CO}_{2}$ Temperature - $773 \mathrm{~K} ; 6$ - Impregnation Coefficient of $\mathrm{ZnCl}_{2}-0.2$; $\mathrm{CO}_{2}$ Temperature - $773 \mathrm{~K} ; 7$ - Impregnation Coefficient of $\mathrm{ZnCl}_{2}-0.4 ; \mathrm{CO}_{2}$ Temperature - $573 \mathrm{~K} ; 8$ - Impregnation Coefficient of $\mathrm{ZnCl}_{2}-0.6 ; \mathrm{CO}_{2}$ Temperature $-773 \mathrm{~K} ; 9$ - Impregnation Coefficient of $\mathrm{ZnCl}_{2}-0.4 ; \mathrm{CO}_{2}$ Temperature $-673 \mathrm{~K}$.

The values of dynamic characteristics obtained as a result of mathematical processing by the Shilov N.A. equation are presented in Table-2. The protective effect time of the adsorbent layer was calculated:

$$
\tau_{\mathrm{p}}=\mathrm{KL}-\tau_{0}
$$

Where, $\tau_{\mathrm{p}}$ is the protective effect time of the adsorbent layer, $\mathrm{h}$;

$\tau_{0}$ is the time loss of protective effect, $h$;

$\mathrm{K}$ is the protective effect coefficient;

$\mathrm{L}$ is the adsorbent layer length, $\mathrm{m}$.

The results show that with the increase of particle size, the value of the «dead layer» - non-working layer - increases, therefore, with the increase of particle size, the dynamic activity of the adsorbent decreases. With the increase of the gas flow rate (Table-3), the protective action time is significantly reduced, i.e. the process proceeds intensively. The dependence of the protective effect time on the adsorbent layer height 
RASĀYAN J. Chem.

Vol. 13 | No. 4 |2332-2339| October - December | 2020

is presented in Table-4. It is seen that the dependence of the protective effect time of the layer on its height is conditioned by two stages. The increase in the height of the working layer with the increase in the total height indicates that the initial layers, considered exhausted, in fact, during the adsorption process, continue to absorb sulfur dioxide and, due to the saturation of the initial layers, the static activity of the spent layers increases.

Table-2: The Value of the Dynamic Characteristics

\begin{tabular}{c|c|c|c|c|c}
\hline $\begin{array}{c}\text { The Particle Size } \\
\text { of the Adsorbent } 1 \\
\cdot 10^{-3}, \mathrm{~m}\end{array}$ & $\begin{array}{c}\text { The } \\
\text { Working } \\
\text { Layer } \\
\text { Height } \\
\lambda \cdot 10^{-3}, \mathrm{~m}\end{array}$ & $\begin{array}{c}\text { The Height } \\
\text { of «dead } \\
\text { layer» } \\
\mathrm{h} \cdot 10^{-3}, \mathrm{~m}\end{array}$ & $\begin{array}{c}\text { Protective } \\
\text { Effect Time } \\
\tau_{3}, \text { hour }\end{array}$ & $\begin{array}{c}\text { The Time } \\
\text { Loss of } \\
\text { Protective } \\
\text { Effect } \\
\tau_{0}, \text { hour }\end{array}$ & $\begin{array}{c}\text { Dynamic } \\
\text { Activity } \\
\mathrm{a}, \mathrm{g} / 100 \mathrm{~g}\end{array}$ \\
\hline Powdery 0.1 & 61 & 38 & 2.5 & 0.9 & 15.9 \\
\hline Granulated 1-3 & 73 & 43 & 2.3 & 0.7 & 14.2 \\
\hline
\end{tabular}

Table-3: The Dependence of Protective Effect Time From the Gas Flow Rate

\begin{tabular}{c|c|c|c}
\hline \multirow{2}{*}{$\begin{array}{c}\text { Particle Size of the } \\
\text { Adsorbent }\end{array}$} & \multicolumn{3}{|c}{ Protective Effect Time $\tau_{3}$, Hour } \\
\cline { 2 - 4 } & \multicolumn{3}{|c}{ Gas Flow Rate $v, \mathrm{~m} / \mathrm{s}$} \\
\cline { 2 - 4 } $10^{-3}, \mathrm{~m}$ & $0.1 \mathrm{~m} / \mathrm{s}$ & $0.3 \mathrm{~m} / \mathrm{s}$ & $0.5 \mathrm{~m} / \mathrm{s}$ \\
\hline Powdery 0.1 & 3.7 & 1.9 & 1.3 \\
\hline Granulated $1-3$ & 3.3 & 1.6 & 1.1 \\
\hline
\end{tabular}

Table -4: The Dependence of Protective Effect Time From the Adsorbent Layer Height

\begin{tabular}{c|c|c|c|c|c}
\hline \multirow{2}{*}{$\begin{array}{c}\text { Particle Size of the } \\
\text { Adsorbent } \\
1 \cdot 10^{-3}, \mathrm{~m}\end{array}$} & \multicolumn{5}{|c}{ Protective Effect Time $\tau_{\mathrm{p}}$ in Hours, for Adsorbent Layer Height $\mathrm{H}$ in $\mathrm{m}$} \\
\cline { 2 - 6 } & 0.01 & 0.03 & 0.06 & 0.09 & 0.12 \\
\hline Powdery 0,1 & 1.9 & 2.5 & 3.3 & 3.9 & 4.3 \\
\hline Granulated 1-3 & 1.6 & 2.3 & 2.9 & 3.6 & 4.1 \\
\hline
\end{tabular}

To test the possibility of using the results to real gas emissions, containing sulfurous anhydride, a series of experiments was carried out in the section of dry electro filters at the metallurgical industry. Gas emissions on the main indicators were characterized by the following data: dust $-100 \mathrm{mg} / \mathrm{m}^{3}$, sulfur dioxide - $(9 \% \pm 0.5)$.

Previous studies have shown that the best adsorbent for the purification of model gas flows among activated coals was peach shell treated by zinc chloride with the impregnation coefficient equal to 0.4 and subsequently treated by heat with the temperature of $\mathrm{CO}_{2}$ equal to $773 \mathrm{~K}$. To test the efficiency of purification of real gas emissions of metallurgical and chemical industries, the same adsorbents were used. The dependence of the purification effect from the contact time of the adsorbent with the gas flow was studied under the same conditions as in experiments with model gas flows.

The presented kinetic curves of the dependence of adsorption from the contact time (Fig.-3 and 4) indicate that the process of adsorption of sulfur dioxide proceeds in the same regularity as in the case of purification of model gas flows. There is also a high rate of adsorption process in the initial time interval (1.5 - 2 hours). With the increase of the contact time to more than (2.5-3) hours, the rate of adsorption by adsorbents decreases sharply. Adsorption equilibrium in the system is achieved after 3 hours of contact of the adsorbent with sulfur dioxide. However, after 2.5 hours of contact with the activated shell with the gas flow, most of the sulfurous anhydride is extracted from the medium. By this time, the efficiency of purification is $(97-98) \%$.

Thus, experiments, carried out with real gas flow, generally confirmed the results obtained in laboratory experiments with model gas flows. Experimental results of industrial tests at the enterprise of the metallurgical industry carried out with the experimental respirator designed and made by us serve as confirmation of the efficiency of use of the activated shell. The respirator is the front part and a cartridge with a filter installed in it. The filter is made in the form of a replaceable cassette, and the filter element is activated coal obtained from the peach shell.

The tests were carried out in comparison with the respirator RPG-67 (with two boxes of the brand «B»). Test results and characteristics of filter cartridges of respirators are given in Table-5. The proposed design 
RASĀYAN J. Chem.

Vol. 13 | No. 4 |2332-2339| October - December | 2020

of the respirator provides a longer service life, the increase of protective effect time, in case of longer exploitation, the possibility of changing the used filter without stopping the respiratory protection. The use of the proposed highly porous activated coal from the fruit shells in the filter of the respirator allows increasing the operational properties by increasing the absorbing capacity of the filter element.

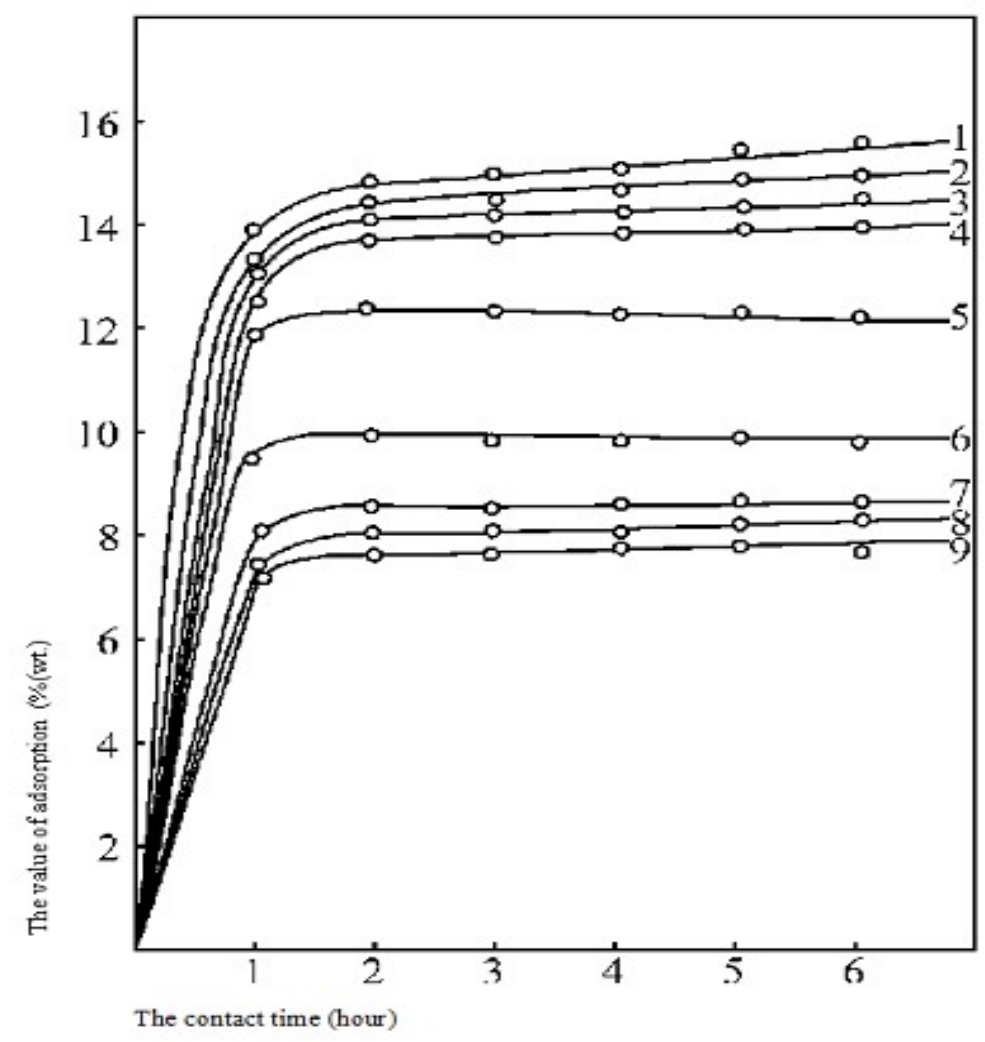

Fig.- 2: Kinetics of Sulfur dioxide Adsorption by Activated Peach Shell: 1 - Impregnation Coefficient of $\mathrm{ZnCl}_{2}-0.4$; $\mathrm{CO}_{2}$ Temperature -773 K; 2 - Impregnation Coefficient of $\mathrm{ZnCl}_{2}-0.4 ; \mathrm{CO}_{2}$ Temperature - $873 \mathrm{~K} ; 3$ - Impregnation Coefficient of $\mathrm{ZnCl}_{2}-0.5 ; \mathrm{CO}_{2}$ Temperature $-773 \mathrm{~K} ; 4$ - Industrial Adsorbent BAU; 5-Impregnation Coefficient of $\mathrm{ZnCl}_{2}-0.3 ; \mathrm{CO}_{2}$ Temperature - $773 \mathrm{~K} ; 6$ - Impregnation Coefficient of $\mathrm{ZnCl}_{2}-0.2 ; \mathrm{CO}_{2}$ Temperature - $773 \mathrm{~K} ; 7$ Impregnation Coefficient of $\mathrm{ZnCl}_{2}-0.4 ; \mathrm{CO}_{2}$ Temperature - $573 \mathrm{~K} ; 8$ - Impregnation Coefficient of $\mathrm{ZnCl}_{2}-0.6$; $\mathrm{CO}_{2}$ Temperature -773 K; 9 - Impregnation Coefficient of $\mathrm{ZnCl}_{2}-0.4$; the Temperature of $\mathrm{CO}_{2}-673 \mathrm{~K}$.

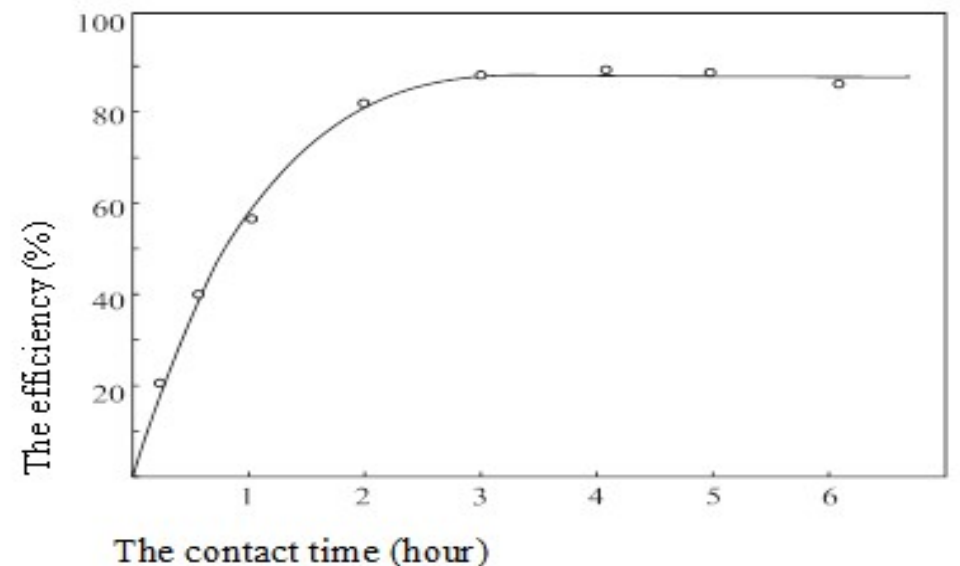

Fig.-3: The Influence Contact Time on the Efficiency of Sulfur dioxide Extraction by Activated Peach Shell 
RASĀYAN J. Chem.

Vol. 13 | No. 4 |2332-2339| October - December | 2020

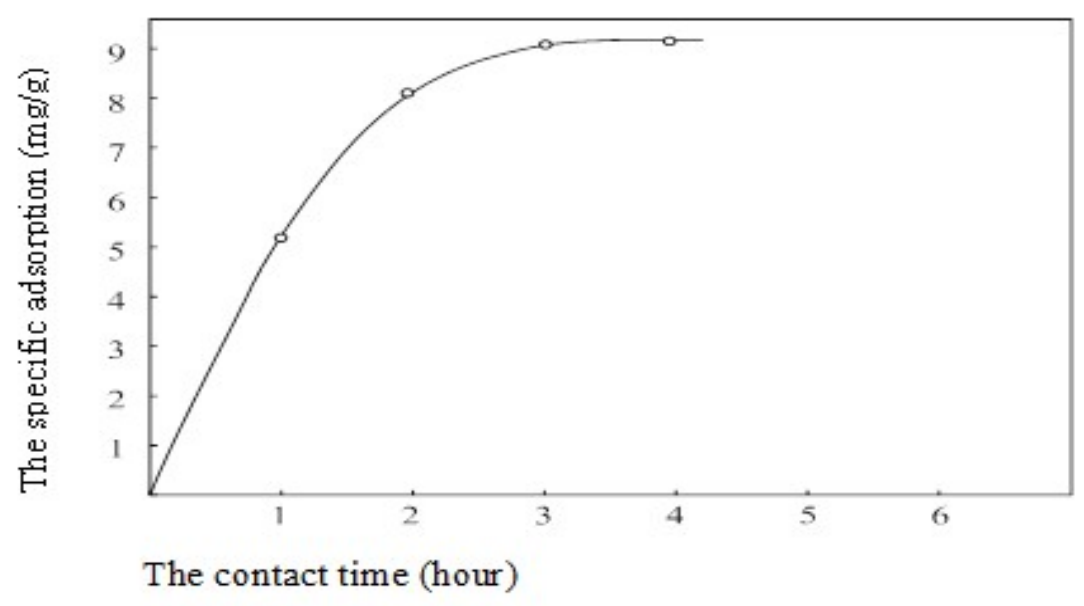

Fig.-4: The Influence Contact Time on the Value Specific Adsorption of Sulfur dioxide by Activated Peach Shell Table - 5: The Results of the Tests and Characteristics of Filter Elements of Respirators

\begin{tabular}{|c|c|c|c|c|c|c|}
\hline \multirow{2}{*}{ 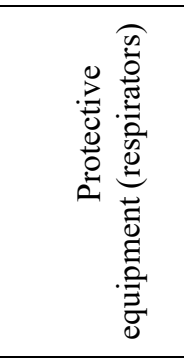 } & \multirow{2}{*}{ 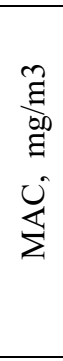 } & \multirow{2}{*}{ 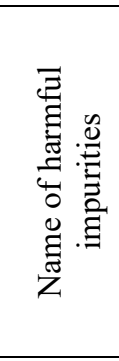 } & \multirow{2}{*}{ 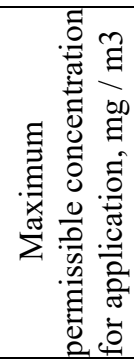 } & \multicolumn{2}{|c|}{$\begin{array}{l}\text { Time of protective action }(\mathrm{h}) \text { at } \\
\text { different concentrations of gases and } \\
\text { vaporous harmful impurities }\end{array}$} & \multirow{2}{*}{ 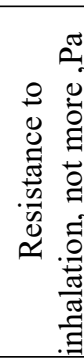 } \\
\hline & & & & $50 \mathrm{mg} / \mathrm{m} 3$ & $\begin{array}{l}\text { Maximum permissible } \\
\text { concentration for } \\
\text { application, } \mathrm{mg} / \mathrm{m} 3\end{array}$ & \\
\hline RPG- 67 & \multirow{3}{*}{10} & \multirow{3}{*}{$\begin{array}{l}\text { sulphur } \\
\text { dioxide }\end{array}$} & \multirow{3}{*}{150} & 30 & 15 & 58.8 \\
\hline $\mathrm{RU}-60 \mathrm{M}$ & & & & 12 & 6 & 78.4 \\
\hline Pilot Sample & & & & 20 & 10 & 72.7 \\
\hline
\end{tabular}

\section{CONCLUSION}

Thus, the established regularities of changes in the adsorption properties of shells during their thermal and chemical activation allowed us to determine the optimal conditions for obtaining modified coals for the processes of effective purification of gases from sulfur dioxide, confirmed by industrial tests.

The most rapid adsorption of sulfur dioxide occurs on the shell treated by $\mathrm{ZnCl}_{2}$ (impregnation coefficient 0.4 ), followed by activation in the $\mathrm{CO}_{2}$ stream at a temperature of $773 \mathrm{~K}$, the pore size of which is easily accessible to sulfur dioxide molecules regardless of their molecular weight and structure.

Maximum adsorption of sulfurous anhydride for activated bone shells occurs in 1.5-2 hours, but already with one-hour gas-phase contact of the adsorbent with sulfurous anhydride, we observe adsorption values of the order of $85-90 \%$ of the maximum achievable.

The values of the dynamic characteristics show that with increasing particle size, the value of the «dead layer» - disabled - increases, therefore, with increasing particle size, the dynamic activity of the adsorbent decreases. With the increase of gas flow rate, the protective effect time is significantly reduced, i.e. the process proceeds intensively.

\section{REFERENCES}

1. H. Kametani, M. Kobayashi, K. Yamada, Journal of the Mining and Metallurgical Institute of Japan, 101, 725(1985). 
RASĀYAN J. Chem.

Vol. 13 | No. 4 |2332-2339| October - December | 2020

2. F. Martinez-Ortiz, A. Molina, C. Serna, Journal of Electroanalytical Chemistry and Interfacial Electrochemistry, 308(1-2), 97(1991), DOI:10.1016/0022-0728(91)85061-S

3. E. Peters, Metallurgical Transactions A, 7, 505(1976).

4. K. Yetilmezsoy, S. Demirel, Journal of Hazardous Materials, 153(3), 1288(2008), DOI: 10.1016/j.jhazmat.2007.09.092

5. M. Din, Z. Hussain, M. Mirza, A. Shah, M. Athar, International Journal of Phytoremediation, 16(9), 889(2014), DOI: 10.1080/15226514.2013.803025

6. G.F. Viana, K.S. Garcia, J.A. Menezes-Filho, Environmental Monitoring and Assessment, 181(1-4), 255(2011), DOI: 10.1007/s10661-010-1827-3

7. K. Chojnacka, Environment International, 36(3), 299(2010), DOI:10.1016/j.envint.2009.12.001

8. C. Asada, Y. Nakamura, F. Kobayashi, Biochemical Engineering Journal, 23, 131(2005), DOI: $10.1016 / \mathrm{j}$. bej.2004.11.004

9. M.K.B. Gratuito, T. Panyathanmaporn, R.A. Chumnanklang, N. Sirinuntawittaya, A. Dutta Bioresource Technology, 99(11), 4887(2008), DOI:10.1016/j.biortech.2007.09.042

10. A. Ahmadpour, D. Do, Carbon, 35(12), 1723(1997), DOI:10.1016/S0008-6223(97)00127-9

11. S. Tamrakar, R. Verma, S.K. Sar, Ch. Verma, Rasayan Journal of Chemistry, 12(2), 455(2019), DOI: $10.31788 /$ RJC.2019.1225106

12. H. Revathi, A. Xavier, M.D. Kumar, T. Saranya, A. Kaviyarasu, T. Murugan, Rasayan Journal of Chemistry, 12(2), 719(2019), DOI:10.31788/RJC.2019.1225094

13. K. Venkata Pravalika, P. Janaki Sriram, P. Karunasri Meghana, K. Ravindhranath, Rasayan Journal of Chemistry, 11(4), 1750(2018), DOI:10.31788/RJC.2018.1145048

14. S.A. Bushumov, T.G. Korotkova, Rasayan Journal of Chemistry, 13(4), 1619(2020), DOI: $10.31788 /$ RJC.2020.1335454

15. S. Prakash Chandar, K. Gunasekaran, Rasayan Journal of Chemistry, 12(3), 1038(2019), DOI: 10.31788/RJC.2019.1235233

16. Z. Zhu, A. Li, L. Yan, F. Liu, Q. Zhang, Journal of Colloid and Interface Science, 316(2), 628(2007), DOI:10.1016/j.jcis.2007.09.016

17. K.K. Singh, U. Singh, A. Yadav, Journal of Chemical and Pharmaceutical Research, 3(1), 338(2011).

18. M.E. Argun, S. Dursun, C. Ozdemir, M. Karatas, Journal of Hazardous Materials, 141(1), 77(2007), DOI: $10.1016 /$ j.jhazmat.2006.06.095

19. S. Babel, T.A. Kurniawan, Journal of Hazardous Materials, 97, 219(2003), DOI:10.1016/S03043894(02)00263-7

20. S.J.T. Pollard, G.D. Fowler, C.J. Sollars, R. Perry, Science of the Total Environment, 116, 31(1992), DOI: 10.1016/0048-9697(92)90363-W

21. A. Ucer, A. Uyanik, F. Aygun, Separation and Purification Technology, 47(3), 113(2006), DOI:10.1016/j.seppur.2005.06.012

22. R. Balaji, S. Sasikala, G. Muthuraman, International Journal of Engineering and Innovative Technology, 3(12), 43(2014).

23. D. Obregón-Valencia, R.M. del Sun-Kou, Journal of Environmental Chemical Engineering, 2(4), 2280(2014), DOI: 10.1016/j.jece.2014.10.004

24. M. Sujatha, A. Geetha, P. Sivakumar, P.N. Palanisamy, European Journal of Chemistry, 5, 742(2008), DOI: 10.1155/2008/418267

25. M. Kwiatkowski, E. Broniek, Colloids and Surfaces A: Physicochemical and Engineering Aspects, 529, 443(2017), DOI:10.1016/j.colsurfa.2017.06.028

26. S.H. Abbas, I.M. Ismail, T.M. Mostafa, H. Sulaymon, Journal of Chemical Science and Technology, 3(4), 74(2014).

27. R. Subramaniam, S.K. Ponnusamy, Water Resources and Industry, 11, 64(2015), DOI: 10.1016/j.wri.2015.07.002

28. G.Z. Memon, M.I. Bhanger, M. Akhtar, Pakistan Journal of Analytical and Environmental Chemistry, 17(1), 77(2016), DOI:10.21743/pjaec/2016.06.012

[RJC-5761/2020] 